\title{
Humanism in medicine. The critical role of pediatricians in autism spectrum disorder
}

\author{
Nicolás Loyacono, M.D. ${ }^{a}$, María L. Ferreira, PhD in Chemistry ${ }^{b}$ and Roberto Iermoli, M.D. ${ }^{a}$
}

\begin{abstract}
In this article, we describe the importance of coexisting medical problems in the diagnosis of autism spectrum disorder (ASD). It is worth noting the role of pediatricians as health care providers trained to assess, test, diagnose, and treat such conditions during childhood. The population diagnosed with ASD is systemically vulnerable. ASD is the name given to a group of symptoms resulting from a systemic, dynamic, chronic encephalopathy according to the model proposed by Martha Herbert, M.D. (Harvard, USA). Based on this model, we may describe the circumstances of patients' families who, in Argentina, are unable to find answers on the coexisting medical problems in the diagnosis of ASD according to the psychoanalytic, genetic, and neurodiversity models. It is necessary to review current models in the setting of humanism in medicine because, so far, results have not been as expected.

Key words: coexisting medical problems, autism spectrum disorder, encephalopathies.
\end{abstract}

http: / / dx.doi.org/10.5546/ aap.2019.eng.195

To cite: Loyacono N, Ferreira ML, Iermoli R. Humanism in medicine. The critical role of pediatricians in autism spectrum disorder. Arch Argent Pediatr 2019;117(3):195-197.

a. Hospital de Clínicas José de San Martín Buenos Aires, Argentina.

b. National Council for Scientific and Technological Research (Consejo Nacional de Investigaciones Científicas y Técnicas, CONICET), Bahía Blanca, Argentina.

E-mail address: Nicolás Loyacono, M.D.: nicoloya@hotmail.com

Funding:

None.

Conflict of interest: None.

Received: 3-5-2018 Accepted: 11-27-2018 a set of emerging symptoms related to a systemic, dynamic, chronic encephalopathy that is potentially reversible (although partially). ${ }^{3}$ The multiple components of this encephalopathy involve several organ systems, not only the central nervous system. In this setting, the role of pediatricians becomes transcendental.

In previous models, pediatricians detected the warning signs and referred their patients for assessment with a specialist. In recent years, the emphasis has been placed on the management of coexisting medical problems at the time of diagnosis, not only on ASD, but also in other neurodevelopmental challenges, e.g., attention deficit disorder (ADD) and hyperactivity disorder (HD), either combined or not. These medical problems are part of pediatricians' competence and span their professional training: from gastrointestinal disorders to immunity, from toxicity to biochemistry and nutrition, from skin disorders to neurological involvement, and even more. The most updated bibliography up to August 2018 contains enough comprehensive, high-quality evidence of the higher prevalence of multiple coexisting medical problems among children, adolescents, and adults with neurodevelopmental challenges (specifically, ASD), ${ }^{5,6}$ compared to the general population. For example, severe vitamin D deficiency or vitamin $\mathrm{D}$ insufficiency, ${ }^{7}$ immune deficiency, ${ }^{8}$ cerebral folate deficiency, ${ }^{9}$ gut microbiota alterations and gastrointestinal problems, ${ }^{10}$ food sensitivity or intolerance, ${ }^{11}$ metabolic abnormalities, ${ }^{12}$ mitochond rial dysfunction, ${ }^{13}$ oxidative stress, ${ }^{14}$ inflammation, ${ }^{15}$ encephalic microglial 
activation, ${ }^{16}$ etc. The scientific bibliography review of the past 5 years includes several consensus reports on the approach to the assessment, diagnosis, and treatment of medical conditions that have been considered controversial and treated as such in pediatric and clinical outpatient clinics. In light of the evidence -both published and mentioned here-, a reformulation is necessary. This is the case of the so-called autoimmune diseases, such as pediatric autoimmune neuropsychiatric disorders associated with streptococcal infections (PANDAS), pediatric infectiontriggered autoimmune neuropsychiatric disorder (PITAND), pediatric acute-onset neuropsychiatric syndrome (PANS), ${ }^{17}$ or others like non-celiac gluten sensitivity (NCGS). ${ }^{18}$ In the case of PANDAS and ASD, a recent study from 2018 by Chain et al. ${ }^{19}$ has established a relation between three common microbial antigens and antineural antibody responses in ASD/PANDAS and suggested that molecular mimicry between the host and the pathogen may play a role in antibody development and potentially lead to neuropsychiatric symptoms in ASD/PANDAS. Therefore, ASD may be complicated with antineuronal antibodies that may develop during infections and contribute to ASD symptoms.

In this context, the families of children, adolescents, and adults with ASD are literally lost, confused, and alone. In the setting of the models applied to ASD in the past 30 years, the exploration of highly important clinical entities, such as NCGS or PANDAS-PITAND-PANS, among others, has been minimized. In this situation, the families of children, adolescents, and adults with ASD are unable to find any answer other than disqualification of their concern for coexisting medical problems in ASD diagnosis and the minimization of everyday situations that they have to face, like lack of sleep, disruptive behaviors, aggressiveness and selfharm, unmanageable symptoms, eating habit and bowel movement alterations, etc. They only have access to information that helps them follow a path that is pointed out as the only one: the management of symptoms.

Numerous publications have demonstrated that mid- and long-term results of ASD models applied in the past 30 years are not as expected. People diagnosed with ASD and intellectual disability have an average life expectancy of 36 years; people diagnosed with ASD but no intellectual disability have 9 times more risks for suicide than the general population. The specific bibliography has confirmed the correlation between coexisting medical problems in ASD diagnosis and a higher risk for mortality. ${ }^{20}$ Anxiety, depression, obsessive compulsive disorder, tics, behavior alterations, aggressiveness and self-harm are extremely prevalent in adult patients with ASD. ${ }^{21-23}$ In the USA, up to $95 \%$ of them live with their parents, and up to $80 \%$ are unemployed after turning 21 years old. ${ }^{23}$

In these circumstances, a different comprehensive approach to ASD should be considered, one that may extend to the entire universe of non-communicable chronic diseases or disorders. Under these premises, the role of pediatricians, primary care physicians, and general practitioners is critical; they are required to urgently take the leadership of interdisciplinary teams that consider the enhancement of physical health in ASD, as recently proposed by the international and local bibliography. ${ }^{24-26}$ At the same time, it is necessary to work on behavioral, relational, psychological, psychoeducational, speech and language, and other aspects, depending on individual needs. Like never before, in 2018, the meaning of ASD, its treatment, and even what is or may be modulable after diagnosis have gone through a Kuhnian paradigm shift, which therefore opens a new path to the expectations of preventing coexisting medical problems in ASD diagnosis and the impact this may have on the individual pathway of people with ASD.

\section{Note}

María Luján Ferreira, PhD in Chemistry, has a son diagnosed with ASD in 2003 and is a Principal Researcher (CONICET) and a scientific advisor for the HCJSM as per Res. 3070/2015, issued by the Board of CONICET.

\section{REFERENCES}

1. Kim YS, LeventhalBL, Koh YJ, FombonneE, et al. Prevalence of autism spectrum disorders in a total population sample. Am J Psychiatry. 2011; 168(9):904-12.

2. Pantelis PC, Kennedy DP. Estimation of the prevalence of autism spectrum disorder in South Korea, revisited. Autism. 2016; 20(5):517-27.

3. Herbert M. Autism: A Brain Disorder, or a Disorder that affects the brain? Clin Neuropsychiatry.2005; 2(6):354-79.

4. Hu VW (ed.). Frontiers In Autism Research: New Horizons For Diagnosis And Treatment. London: World Scientific Publishing Co; 2014.

5. Loyacono N, Artigas D, Gerbi MD, Gertiser MA. Trastornos del Espectro Autista. Enfoque Integrador: El arte de lo posible. Buenos Aires: Ediciones Globales; 2015.

6. Muskens JB, Velders FP, Staal WG. Medical comorbidities 
in children and adolescents with autism spectrum disorders and attention deficit hyperactivity disorders: a systematic review. Eur Child Adolesc Psychiatry. 2017; 26(9):1093-103.

7. Saad K, Abdel-Rahman AA, Elserogy YM, Al-Atram AA, et al. Vitamin D status in autism spectrum disorders and the efficacy of vitamin D supplementation in autistic children. Nutr Neurosci. 2016; 19(8):346-51.

8. Careaga M, Rogers S, Hansen RL, AmaralDG, etal.Immune Endophenotypes in Children With Autism Spectrum Disorder. Biol Psychiatry. 2017; 81(5):434-41.

9. Frye RE, Sequeira JM, Quadros EV, James SJ, et al. Cerebral folate receptor autoantibodies in autism spectrum disorder. Mol Psychiatry. 2013; 18(3):369-81.

10. Li Q, Han Y, Dy ABC, Hagerman RJ. The Gut Microbiota and Autism Spectrum Disorders. Front Cell Neurosci. 2017; 11:120.

11. Whiteley P. Food and the gut: relevance to some of the autisms. Proc Nutr Soc. 2017; 76(4):478-83.

12. Khemakhem AM, Frye RE, El-Ansary A, Al-Ayadhi L, et al. Novel biomarkers of metabolic dysfunction is autism spectrum disorder: potential for biological diagnostic markers. Metab Brain Dis. 2017; 32(6):1983-97.

13. Rose S, Bennuri SC, Murray KF, Buie T, et al. Mitochondrial dysfunction in the gastrointestinal mucosa of children with autism: A blinded case-control study. PLoS One. 2017; 12(10):e0186377.

14. El-Ansary A, Bjørklund G, Chirumbolo S, Alnakhli OM. Predictive value of selected biomarkers related to metabolism and oxidative stress in children with autism spectrum disorder. Metab Brain Dis. 2017; 32(4):1209-21.

15. Prata J, Santos SG, Almeida MI, Coelho R, et al. Bridging Autism Spectrum Disorders and Schizophrenia through inflammation and biomarkers-pre-clinical and clinical investigations. J Neuroinflammation. 2017; 14(1):179.

16. Suzuki K, Sugihara G, Ouchi Y, Nakamura K, et al. Microglial activation in young adults with autism spectrum disorder. JAMA Psychiatry. 2013; 70(1):49-58.

17. Koplewicz H. Special Issue: PANS-PANDAS Treatment Guidelines. JChild Adolesc Psychopharmacol. 2017; 27(7):561.
18. Catassi C, Elli L, Bonaz B, Bouma G, et al. Diagnosis of Non-CeliacGluten Sensitivity(NCGS): TheSalernoExperts' Criteria. Nutrients. 2015; 7(6):4966-77.

19. Chain JL, Cox CJ, Álvarez KM, Menéndez CM, et al. Anti-neuronal and anti-microbial immunity link CaMKII and autism spectrum disorder with pediatric acute-onset neuropsychiatric syndrome. J Immunol. 2018; 200(Suppl 1):166.63.

20. Cusack J, Shaw S, Spiners J, Sterry R. Personal tragedies, public crisis. The urgent need for a national response to early death in autism. Autistica. 2016. [Accessed on: November $28^{\text {th }}, 2018$ ]. Available at: https: / / www.autistica. org.uk/downloads / files / Personal-tragedies-public-crisisONLINE.pdf.

21. Hirvikoski T, Mittendorfer-Rutz E, Boman M, Larsson $\mathrm{H}$, et al. Premature mortality in autism spectrum disorder. $\mathrm{Br}$ J Psychiatry. 2016; 208(3):232-8.

22. Guan J, Li G. Injury Mortality in Individuals With Autism. Am I Public Health. 2017; 107(5):791-3.

23. Drexler Autism Institute National Autism Indicators Report. Drexler University. 2015, 2016 y 2017. [Accessed on: November $\left.28^{\text {th }}, 2018\right]$. Available at: http: / / drexel.edu / autismoutcomes/publications-and-reports/nat-autismindicators-report/.

24. Perrin JM, Coury DL, Klatka K, Winklosky B, et al. The Autism Intervention Research Network on Physical Health and the Autism Speaks Autism Treatment Network. Pediatrics. 2016; 137(Suppl 2):S67-71.

25. Lajonchere C, Jones N, Coury DL, Perrin JM. Leadership in health care, research, and quality improvement for children and adolescents with autism spectrum disorders: Autism Treatment Network and Autism Intervention Research Network on Physical Health. Pediatrics. 2012; 30(Suppl 2):S62-8.

26. Loyacono N, Ferreira ML, Iermoli RH. Trastornos del Espectro Autista. Enfoque Integrador: Del arte de lo posible a la Investigación puesta en Práctica. Buenos Aires: Ediciones Globales; 2018. 